\title{
LAS LEYES COMUNITARIAS EN ITALIA DESPUÉS DE LA LEY BUTTIGLIONE ${ }^{1}$
}

\author{
ANTONI ROIG BATALLA \\ Profesor Titular de Derecho Constitucional \\ Universidad Autónoma de Barcelona
}

SUMARIO

I. Introducción.

II. Los orígenes de la Ley Comunitaria.

III. El primer modelo general de ley comunitaria: la Ley nacional 86/1989, de 9 de marzo (Ley La Pergola), modificada posteriormente por la Ley Comunitaria19951997.

IV. El modelo actual de ley comunitaria: la Ley n.11/2005, de 4 de febrero, conocida como la Ley Buttiglione.

V. Desarrollo del Derecho Europeo directamente mediante la Ley Comunitaria.

VI. Desarrollo del Derecho Europeo mediante autorizaciones al Gobierno, contenidas en la ley comunitaria.

VII. Dictamen opcional de las Comisiones parlamentarias.

VIII. La posición de la Ley Comunitaria.

IX. Conclusiones.

1 Este estudio es una ampliación y actualización de la Comunicación presentada en el II Congreso de la Asociación de Constitucionalistas de España, que tuvo lugar en la Facultad de Derecho de Córdoba, los días 25 y 26 de septiembre de 2003, y que se publicó, como Working Paper en el libro dirigido por el Profesor Pablo LUCAS MURILLO DE LA CUEVA (ed.), Gobierno y Constitución. Actas del II Congreso de la Asociación de Constitucionalistas de España, Tirant Lo Blanch, 2005. 


\section{INTRODUCCIÓN}

El estudio de las fuentes del Derecho italianas ofrece siempre elementos de reflexión para el constitucionalista español. Podríamos destacar al menos tres buenas razones para ello. En primer lugar, la ordenación del sistema de fuentes siempre ha merecido una especial atención en la doctrina constitucional italiana, que no ha excluido tampoco a la potestad reglamentaria de su ámbito de análisis ${ }^{2}$. En segundo lugar, las semejanzas con el ordenamiento español son notables, pues hay coincidencia en uno de los aspectos más significativos: la existencia de normas gubernamentales con rango de ley ${ }^{3}$. Finalmente, al igual que sucede con los otros países de la Unión, el desarrollo de las Directivas comunitarias plantea problemas comunes a todos los Estados miembros ${ }^{4}$. Por consiguiente, las soluciones adoptadas aunque no deban ser necesariamente compartidas, sí pueden servir para valorar, con más fundamento si cabe, las medidas adoptadas en nuestro país 5 . Este es el único objetivo de este análisis, y de ninguna manera se pretende una traslación automática a nuestro país de la técnica de la Ley Comunitaria, no exenta tampoco de críticas en Italia.

\section{LOS ORÍGENES DE LA LEY COMUNITARIA}

La Ley Comunitaria es una ley estatal ordinaria, normalmente con vigencia anual, que tiene el cometido específico de asegurar un desarrollo regular del

2 Algunos autores clásicos serían, por ejemplo, Giuliano AMATO, Enzo CHELI, Vezio CRISAFULLI, Carlo ESPOSITO, FODERARO, Sergio FOIS, Sandro MERZ, Temistocle MARTINES y Costantino MORTATI. Más recientemente, han destacado en el estudio de las fuentes italianas, Lorenza CARLASSARE, Marta CARTABIA, Augusto CERRI, Angelo Antonio CERVATI, Ugo de SIERVO, Ricardo GUASTINI, Nicola LUPO, Franco MODUGNO, Livio PALADIN, Alessandro PIZZORUSSO, Giuseppe Ugo RESCIGNO, Antonio RUGGERI, Federico SORRENTINO, Giovanni TARLI BARBIERI y Gustavo ZAGREBELSKY, entre otros.

3 El sistema de fuentes italiano conoce tanto la figura del decreto-ley como la del decreto legislativo, y ello acerca los dos países, que siguen siendo en la actualidad una excepción en el panorama internacional, por cuanto no es habitual atribuir al Gobierno la potestad de dictar normas con el mismo rango de la ley. Normalmente, se requiere para ello una expresa habilitación legal, que legitima al Gobierno para modificar leyes vigentes.

4 Básicamente, el desarrollo comunitario requiere de una norma con rango legal que pueda ser modificada de manera rápida y reiterada. El decreto legislativo, y en menor grado una técnica deslegalizadora, suelen ser las opciones preferidas, aunque la delegación legislativa plantea un problema. En efecto, la habilitación suele ser puntual, y en cambio, se requeriría un instrumento que autorizara de manera continuada o general, no restringido a un único desarrollo. Debería utilizarse, en consecuencia, una ley de delegación abierta a múltiples desarrollos durante un período temporal más o menos amplio. Ello se conoce en Italia como el decreto legislativo corrector o reiterativo. Evidentemente, esta autorización general requiere una justificación constitucional nueva, pues no debe olvidarse que la potestad reglamentaria con rango de ley es una excepción constitucional.

5 Cabe preguntarse, por ejemplo, cuál es la razón para que el papel del decreto legislativo sea tan distinto en el desarrollo del derecho comunitario en ambos países. 
Derecho europeo, respetando también el plazo establecido a tal fin ${ }^{6}$. A esta función inicial se le han añadido otras recientemente, como veremos. La expresión "Ley Comunitaria" proviene del artículo 2 de la Ley n.86, de 9 de marzo de 1989, conocida como Ley La Pergola . Con esta disposición se quería dar respuesta a una situación de dificultades graves e incumplimiento de la ejecución del Derecho europeo por parte del Estado italiano ${ }^{8}$. Hasta la aparición de la técnica de la Ley Comunitaria en 1989, la transposición de las Directivas en Italia había seguido dos vías: la deslegalización y la delegación legislativa. La doctrina italiana solía criticar la delegación legislativa por considerar que no respetaba las exigencias constitucionales establecidas en el artículo 76 C.I. en cuanto a los límites temporales, el objeto y la omisión o insuficiencia de los principios y criterios directivos 9 . Se trataba de un instrumento normativo que tomaba el nombre del instituto previsto en el artículo 76 C.I., pero que sustancialmente era una delegación en blanco. Se atribuía al Gobierno, en efecto, un poder indeterminado, en ocasiones dirigido a desarrollar disposiciones europeas futuras, sin límite temporal ni fijación de los principios y de los criterios directivos ${ }^{10}$. Por otro lado, la falta de coordinación provocaba numerosos conflictos entre las Regiones y el Estado, y entre el Parlamento y el Gobierno ${ }^{11}$. Por ello, se buscó un mecanismo más racional y eficaz, y la Ley Comunitaria fue la solución propuesta.

6 Una visión general, aunque requiere actualización, en CELOTTO, Alfonso, "Legge comunitaria", Enciclopedia Giuridica, 1995, pp. 1-12. Otros trabajos más recientes son los de Arianna PITINO, Verso una nuova legge comunitaria. Stato e Regioni tra l'attuazione del Titolo V e il nuovo Trattato che adotta una costituzione per l'Europa, Ed. Giappichelli, Turín, 2005; Adele ANZON, "L'attuazione degli obblighi comunitarie: legge comunitaria e ruolo delle Regioni", en Sergio PANUNZIO (ed.), Costituzionalisti e l'Europa (I). Riflessioni sui mutamenti costituzionali nel processo d'integrazione europea. Atti del Seminario svoltosi a Roma, presso la Facoltà di Giurisprudenza della LUISS-Guido Carli, Giuffrè, Milán, 2002; Alberto MENCARELLI, "Riflessioni sulla legge comunitaria come legge organica in senso materiale", en Silvano LABRIOLA (ed.), Il Parlamento repubblicano (1948-1998), Giuffrè, Milán, 1999; Alberto MENCARELLI, "La legge comunitaria tra vincoli di attuazione del diritto comunitario e autovincoli legislativi dei procedimenti di ricepimento", en Franco MODUGNO (ed.), Trasformazioni della funzione legislativa, Giuffrè, Milán, 1999 y Raffaele PERAINO, "Il ruolo della comissione politiche dell'Unione nell'esame del disegno di legge comunitaria: problematiche attuali e prospettive di riforme", en Silvo TRAVERSA y Antonio CASU (eds.), Il Parlamento nella transizione, Giuffrè, Milán, 1998.

7 El nombre corresponde al entonces Ministro para la Coordinación de las Políticas Comunitarias.

8 TIZZANO, A., "La nouvelle loi italienne pour l'exécution des obligations communautaires", Revue du Marché Commun, 1990, pp. 532-540. Desde 1958 a 1989, el Tribunal de Justicia ha dictado 280 decisiones condenatorias, de las cuales 114 corresponden al Estado italiano. Otro dato significativo lo ofrece CELOTTO, en su trabajo antes citado: La Ley n.42, de 9 de febrero de 1982, delega al Gobierno el desarrollo de casi cien directivas comunitarias, que habían superado ampliamente el plazo previsto para ello, en ocasiones desde hacía casi veinte años.

9 A. CELOTTO analiza las críticas principales en su contribución "Legge comunitaria", Enciclopedia Giuridica, vol. XVIII, Roma, 1995, 2.

10 Ibidem.

11 Sobre los conflictos mencionados, puede consultarse la bibliografía contenida en las notas 384 y 385 del trabajo de CARMELI, Sara, La Constitution italienne et le droit communautaire. Études de Droit comparé, L'Harmattan, 2002. 
Antes de pasar a su estudio en el apartado siguiente, conviene describir brevemente las características principales de su antecedente inmediato: la Ley Fabbri, n. 183, de 16 de abril de 1987. La primera novedad consistió en la regulación institucional de los órganos de coordinación de las políticas comunitarias (ministro ad boc y Departamento correspondiente), que databan de inicios de los años ochenta. Asimismo, la Ley previó la comunicación de los proyectos de actos comunitarios, así como de los textos definitivamente adoptados, a las Cámaras y a las Regiones. El instrumento elegido no era nuevo, pues se basaba en el decreto legislativo. Sin embargo, las previsiones eran más acordes con la Constitución, pues se establecía un mecanismo frente a directivas ya aprobadas, que tenía una vigencia anual y mediante el cual se fijaban unos principios y unas directrices ${ }^{12}$.

\section{EL PRIMER MODELO GENERAL DE LEY COMUNITARIA: LA LEY NACIONAL 86/1989, DE 9 DE MARZO (LEY LA PERGOLA), MODIFICADA POSTERIORMENTE POR LA LEY COMUNITARIA 1995-1997}

La Ley número 86, de 9 de marzo de 1989, Ley La Pergola, fue una norma innovadora que pretendió servir de modelo general para el desarrollo del Derecho europeo, y estableció al efecto las leyes comunitarias anuales. La novedad de la Ley La Pergola fue la adopción de un método estructurado, inmediato y constante de transposición del Derecho europeo mediante un instrumento clave, la ley comunitaria. Por ello, se abandonó el recurso al decreto legislativo, que desbloqueaba periódicamente una situación de retraso estructural. De esta manera, esta Ley fue la primera regulación del Estado italiano que pretendió, no ya dar un desarrollo sustantivo a una norma europea, sino regular formalmente el propio procedimiento de recepción mismo. Por otro lado, otro aspecto destacable de la ley fue su vocación de otorgar a las Cámaras un papel más relevante en la elaboración y aplicación del Derecho europeo. En cuanto a la naturaleza jurídica del instituto, la doctrina considera a la Ley La Pergola un ejemplo de ley "atípica", al ser una ley ordinaria que contiene una regulación sobre la producción jurídica. La ley comunitaria, por su parte, es también una ley ordinaria, situada jerárquicamente en el mismo nivel que la Ley La Pergola.

Las características principales de la ley comunitaria, según el modelo inicial de 1989, eran las siguientes. La iniciativa legislativa, al igual que sucede con la ley presupuestaria, estaba reservada al Gobierno, a propuesta del Ministro para la coordinación de las Políticas Comunitarias, que debía presentar antes del 31 de marzo el proyecto a las Cámaras ${ }^{13}$. El texto se acompañaba de un informe que contenía la jurisprudencia del Tribunal de Justicia de las Comunida-

12 CELOTTO, Alfonso, op.cit., 3.

13 Este plazo inicial ha sido posteriormente modificado, como veremos. 
des Europeas y los incumplimientos del Estado italiano. La fase de discusión y aprobación no había merecido, en cambio, ninguna atención en la Ley $L a$ Pergola, y fueron las Cámaras las que adaptaron los reglamentos parlamentarios correspondientes para establecer el procedimiento a seguir, previendo la participación de la Comisiones respectivas especializadas en las políticas europeas. La aprobación seguía el procedimiento ordinario y, por ello, esta falta de especialización llevó a varias reformas del procedimiento legislativo, tendentes a reforzar el papel del Parlamento en la fase de formación del Derecho comuni$\operatorname{tario}^{14}$.

Por todo lo dicho, el lector ya supondrá que al tratarse de una simple ley ordinaria, la Ley La Pergola no pudo impedir que algunas de las leyes anuales contuvieran regulaciones generales que alteraban el modelo inicial ${ }^{15}$. Así, la quinta ley comunitaria, n.128/1998, para el período 1995-1997, introdujo en su momento novedades significativas ${ }^{16}$. Los artículos 13 y 14 reforzaban, en primer lugar, el papel del Parlamento en la fase ascendente y descendente de elaboración del Derecho europeo. De esta manera, el Ministro competente para la coordinación de las políticas europeas tenía la obligación de comunicar a las Cámaras no sólo los actos normativos comunitarios (reglamentos, directivas y recomendaciones), sino también los simples actos de orientación política ${ }^{17}$. Se transmitían también a las Regiones y a las Provincias autónomas los proyectos de actos normativos y de orientación política. Otra novedad introducida por la Ley 128/1998, era que el Gobierno -más concretamente el Ministro competente para la coordinación de las políticas europeas - tenía un plazo que vencía el 31 de enero de cada año, para presentar el proyecto de ley comunitaria.

14 Las leyes comunitarias 1995-1997 y 1998 realizaron importantes modificaciones al procedimiento de adopción de la ley comunitaria. Véase, al respecto, FIORAVANTI, C., "Modifiche e integrazioni alla legge la Pergola", Rivista di Diritto agrario, 1999, pp. 95-104.

15 Por ejemplo, el art. 3 de la Ley n. 146/1994 (Ley Comunitaria para 1993) modificó el art. 4, apartado 4, de la Ley La Pergola, y transformó el dictamen de la Comisión parlamentaria sobre los reglamentos autorizados (deslegalización), que era siempre obligatorio anteriormente, en necesario únicamente cuando así lo dispone la ley comunitaria.

16 Ley de 24 de abril de 1998, n.128 (Ley Comunitaria1995-1997). Con anterioridad, fueron aprobadas, siguiendo el esquema de la Ley La Pergola, otras cuatro leyes comunitarias: Ley de 29 de diciembre de 1990, n.428 (Ley Comunitaria para 1990); Ley de 19 de febrero de 1992, n.146 (Ley Comunitaria para 1991); Ley de 22 de febrero de 1994, n. 146 (Ley Comunitaria para 1993) y Ley de 6 de febrero de 1996, n. 52 (Ley Comunitaria para 1994). La Ley de 19 de diciembre de 1992, n. 489 fue considerada una "mini-comunitaria". Más adelante, se adoptaron las leyes comunitarias n. 25, de 5 de febrero de 1999, (Ley Comunitaria para 1998), la Ley n.526, de 21 de diciembre de 1999 (Ley Comunitaria para 1999) y la Ley n.422, de 29 de diciembre del 2000 (Ley Comunitaria para el 2000). Puede consultarse un resumen de los principales contenidos y novedades de estas leyes comunitarias en CARMELI, Sara, La Constitution italienne..., op.cit., 228-245. Con posterioridad, han aparecido nuevas leyes comunitarias: Ley Comunitaria de 2001, de 1 de marzo de 2002, n.39, la Ley Comunitaria para 2002, de 3 de febrero de 2003, n. 14, la Ley Comunitaria para 2003, de 31 de octubre de 2003, n.306, la Ley Comunitaria para 2004, de 18 de abril de 2005, n.62 y la Ley Comunitaria para 2005, de 25 de enero de 2006, núm. 29. Pueden consultarse en la dirección www.politichecomunitarie.it.

17 Se incluyen, por consiguiente, los actos en materia de justicia y de asuntos internos. 
Sin embargo, el retraso en la adopción de las leyes comunitarias llevó, en no pocas ocasiones, a acumular varias leyes comunitarias pendientes en una, y excepcionalmente a omitir una ley comunitaria, como sucedió en $1992^{18}$. Asimismo, novedosa era la previsión de información adicional, junto al proyecto de ley comunitaria, relativa a aquellas Directivas no incluidas en la Ley Comunitaria y que, en cambio, tenían un plazo de aplicación que había vencido, o vencía en el año en curso. El objetivo era obligar a justificar la omisión y permitir al Parlamento suplir las lagunas detectadas.

Por otro lado, las Regiones también se beneficiaron de las novedades de la Ley 128/1998. En efecto, las Regiones podían también aplicar las Directivas comunitarias, en aquellos supuestos de competencia concurrente, equiparados ahora a los de competencia exclusiva. La Ley núm. 128/1998 autorizó a las Regiones a actuar directamente en aplicación de la Directiva europea, sin necesidad de esperar la autorización de la primera Ley Comunitaria anual posterior a la notificación de la Directiva, como acontecía hasta la fecha ${ }^{19}$. Ahora bien, las leyes regionales de aplicación debían indicar el número de Directiva aplicada, como medida pensada para favorecer la identificación de las normas regionales de desarrollo europeo. Por otro lado, la Conferencia Estado-Regiones, en su sesión comunitaria, había admitido, por primera vez, el poder de convocatoria regional, y trasladaría las Cámaras los acuerdos y debates habidos en su seno. Asimismo, la Conferencia podría emitir un dictamen sobre el proyecto de ley comunitaria, tal como había sugerido buena parte de la doctrina.

\section{EL MODELO ACTUAL DE LEY COMUNITARIA: LA LEY N.11/2005, DE 4 DE FEBRERO, CONOCIDA COMO LA LEY BUTTIGLIONE ${ }^{20}$}

Aunque la Ley La Pergola fue cualificada como provisional en su momento por parte del propio La Pergola, se aplicó, con las modificaciones ya comentadas, hasta 2005. Las principales innovaciones que aporta la nueva regulación general de la ley comunitaria, la Ley Buttiglione, son las siguientes ${ }^{21}$ :

18 Éste es el caso de la Ley Comunitaria128/1998, para 1995-1997, que acumula tres leyes comunitarias en una sola. Con anterioridad, la Ley Comunitaria para 1994 fue adoptada en 1996 (ley 52/1996).

19 Sobre la Ley núm. 128, de 24 de abril de 1998 (Ley Comunitaria1995-1997), DONATI, Filippo, “La nuova disciplina della partecipazione italiana alla elaborazione ed all'attuazione del Diritto comunitario contenuta nella Legge 24 aprile 1998, n.128 (Legge comunitaria 1995-1997)", en DE SIERVO, Ugo (ed.), Osservatorio sulle fonti. 1998, Giappichelli, Turín, pp. 1-16.

20 En referencia al Ministro para las Políticas Comunitarias.

21 Pese a su pretendido carácter de ley general sobre el desarrollo del Derecho europeo, la Ley $11 / 2005$, de 4 de febrero ha sido ya modificada por la Ley Comunitaria para 2005, de 25 de enero de 2006, núm. 29. Concretamente, el art. 10, apartado 4, relativo a los decretos legislativos que desarrollan el Derecho europeo y están autorizados por una ley de bases que no es la ley comunitaria, incorpora una puntualización. Más destacable es la inclusión de un artículo nuevo y amplio, el 29 bis, a resultas también de la Ley Comunitaria para 2005, en su artículo 18. 
La finalidad de la norma ha cambiado en relación al primer modelo. En efecto, no se trata ya solamente de realizar una aplicación respetuosa de las obligaciones contraídas por Italia en materia comunitaria, así como de cumplir los plazos de desarrollo legislativo previstos. Ello permitía considerar a la Ley $\mathrm{La}$ Pergola como una ley pensada casi exclusivamente para la fase descendente o de ejecución del derecho comunitario ${ }^{22}$. En cambio, la Ley Buttiglione prevé hasta cinco artículos pensados específicamente para la fase ascendente ${ }^{23}$. También los actos contemplados se amplían, pues además de los actos comunitarios, se incluyen las obligaciones derivadas de las decisiones y de los acuerdos de cooperación policial y judicial en materia penal. Por lo demás, se afirma expresamente la vigencia de los principios de subsidiariedad, de proporcionalidad, de eficiencia, de transparencia y de participación ciudadana en la actuación italiana.

Se crea un Comité Interministerial para los Asuntos comunitarios europeos (CIACE) con la obligación de coordinar la fase ascendente y de impulsar la fase descendente. Cuando el tema pueda ser de interés para los entes territoriales, está prevista la posibilidad de una representación regional y local reducida. El CIACE dispone de un Comité técnico que, en caso de afectar a temas de competencia regional, realizará sus sesiones en el sí de la Conferencia Estado-Regiones.

En cuanto a la fase ascendente, otra novedad significativa consiste en la ampliación de los sujetos involucrados, pues se contempla la participación de los entes locales en la Conferencia Estado-Ciudades y de los agentes sociales en la CNEL. También destacable es la previsión de una "reserva de examen", mediante la cual el Gobierno puede paralizar los trabajos del Consejo de Ministros de la Unión Europea a la espera de que, en sede interna, se llegue a una propuesta en la fase ascendente ${ }^{24}$.

También en la fase descendiente o aplicativa pueden destacarse innovaciones. De forma general, la información sobre los actos normativos y preparatorios de la Unión y el estado del desarrollo, así como las medidas propuestas incluye no sólo al Gobierno y a las Cámaras, sino también a las Regiones y Provincias Autónomas. El objetivo es poder presentar, con toda la información necesaria, y como muy tarde el 31 de enero, el proyecto de Ley Comunitaria del año correspondiente. Y es que la Ley Comunitaria sigue siendo un elemento esencial en la fase de desarrollo del derecho europeo. Ahora bien, su importancia ha menguado desde el momento que las Regiones disponen de capacidad legislativa para desarrollar las Directivas europeas, en materias de su competencia, sin necesidad de esperar a la ley comunitaria ${ }^{25}$. Este creciente papel

22 Únicamente el art. 1 bis de la Ley 86/1989, que fue incorporado por la Ley n 422/2000, contenía una previsión ascendente. Se titulaba: “Transmisión al Parlamento y a las regiones de los proyectos de actos comunitarios".

23 Artículos 3 a 7 de la Ley 11/2005.

24 De hecho, hay dos reservas de examen: una, prevista en el artículo 4 de la Ley 11/2005, a favor de las Cámaras parlamentarias; y otra, que se encuentra en el artículo 5 de la misma Ley, en beneficio de la Conferencia Estado-Regiones.

25 Artículo 16.1 de la Ley 11/2005. El artículo 16.4 de la misma Ley, con todo, habilita al Gobierno para armonizar los desarrollos regionales de las Directivas europeas. 
de las Regiones ha llevado incluso a la adopción de leyes comunitarias regionales ${ }^{26}$.

Por último, puede destacarse otra novedad, consistente en una cláusula de derogación expresa, con la cual la Ley Buttiglione pretende evitar que una simple Ley Comunitaria puntual modifique el procedimiento general aquí dibujado ${ }^{27}$.

Si analizamos ahora el contenido de la ley comunitaria, podemos llegar a distinguir los siguientes supuestos: en primer lugar, la Ley Comunitaria puede fijar directamente el desarrollo de la Directiva europea; por otro lado, ésta puede prever una delegación legislativa al Gobierno; otra posibilidad consiste en autorizar una deslegalización mediante reglamentos; y finalmente, la Ley Comunitaria puede ser aplicada mediante simples actos administrativos. Veamos con un poco más de detalle cada una de estas posibilidades en los capítulos siguientes.

\section{DESARROLLO DEL DERECHO EUROPEO DIRECTAMENTE MEDIANTE LA LEY COMUNITARIA}

La Ley Comunitaria dispone directamente sobre las obligaciones fijadas en el Derecho europeo básicamente en dos supuestos: cuando el desarrollo no supone demasiada complejidad técnica, y cuando éste requiere la derogación o modificación de disposiciones nacionales contrarias al Derecho europeo. En efecto, la mera inaplicación es un instrumento que se considera insuficiente a estos efectos ${ }^{28}$. Un supuesto particular consiste en la modificación o derogación de normas internas que hayan sido objeto de un procedimiento sancionador por parte de la Comisión de las Comunidades Europeas. También es destacable la derogación en cumplimiento de sentencias del Tribunal de Justicia de las Comunidades Europeas ${ }^{29}$.

A pesar de que la primera Ley Comunitaria contenía un amplio desarrollo directo de las obligaciones comunitarias, ello cambió con las leyes posteriores. En efecto, el contenido de las leyes comunitarias segunda, tercera y cuarta evidenciaba una disminución de la regulación directa. Sin embargo, la quinta Ley Comunitaria(1995-1997) supuso de nuevo un cambio de tendencia al contemplar una regulación directa destacable, ya sea para derogar disposiciones nacionales incompatibles con el Derecho europeo, o bien para fijar directamente la aplicación de la Directiva comunitaria. Más recientemente, la Ley Co-

26 Por ejemplo, Friuli-Venezia Giulia ha aprobado recientemente una Ley Comunitaria regional de fecha 6 de mayo de 2005, n. 11.

27 Artículo 21 de la Ley Buttiglione.

28 CELOTTO, Alfonso, op.cit., p. 4.

29 Así, por ejemplo, la Ley de 11 de enero de 2001, n.7 fue derogada por el art. 6 de la Ley Comunitaria para 2004, en cumplimiento de la Sentencia del Tribunal de Justicia de las Comunidades Europeas (en adelante, TJCE) de 15 de enero de 2002,C439/99. 
munitaria para 2004 contiene igualmente una notable regulación directa, que desciende en ocasiones hasta el rango reglamentario ${ }^{30}$. Esta tendencia incluso parece acentuarse con la Ley Comunitaria para 2005, cuyo contenido es fundamentalmente regulación directa ${ }^{31}$.

En conclusión, la transposición de la Directiva mediante la Ley Comunitaria suele reservarse, como hemos dicho, para los supuestos de disposiciones europeas de contenido más simple, o bien cuando deben únicamente derogarse o modificarse ciertas normas internas ${ }^{32}$. Con todo, el contenido regulador es significativo en bastantes ocasiones, en las cuales la Ley Comunitaria asemeja una auténtica ley de desarrollo directo del Derecho europeo.

\section{DESARROLLO DEL DERECHO EUROPEO MEDIANTE AUTORIZACIONES AL GOBIERNO, CONTENIDAS EN LA LEY COMUNITARIA}

\section{VI.1. Delegación Legislativa}

Como hemos visto, la delegación legislativa ha sido el instrumento habitual de desarrollo del Derecho europeo durante muchos años. En la actualidad, a pesar de la previsión de la ley comunitaria, el decreto legislativo sigue siendo uno de los procedimientos habituales u ordinarios de desarrollo de las Directivas, pues supone entre un cuarto y la mitad de las transposiciones previstas en la ley comunitaria ${ }^{33}$. Este número relevante de delegaciones legislativas contrasta con la opción que parece priorizar la Ley La Pergola, esto es, el desarrollo reglamentario y administrativo ${ }^{34}$. En efecto, la referencia al decreto legislativo es, en esta Ley de 1989, sumamente lacónica ${ }^{35}$. A pesar de todo, el decreto le-

30 En el artículo 7 de la Ley Comunitaria para 2004 se modifica un decreto ministerial; asimismo, el artículo 9 da recepción a la Directiva 2003/6/CE, el artículo 24 modifica varias disposiciones sobre obras públicas y el artículo 29 modifica la ley de seguridad laboral para cumplir una sentencia del TJCE. Otro ejemplo notable lo constituye el artículo 9 de la Ley Comunitaria para 2003, que modifica el decreto legislativo n. 432, de 19 de noviembre de 1998, sobre inspecciones y controles veterinarios. También el art. 17 de la Ley Comunitaria para 2005 modifica un decreto presidencial.

31 Así, los artículos 2 y 18 modifican la Ley Comunitaria para 2004; y los artículos 9, 10, 13, 14, 16, 17 (modificación reglamentaria), 19, 20, 21, 23, 24 y 26 son modificaciones de normas con rango de ley.

32 Así, por ejemplo, el art. 6 de la Ley Comunitaria de 2003 modifica varios artículos de la Ley de acceso a la profesión notarial sustituyendo la mención única al Estado italiano por una referencia al "Estado italiano u otro Estado de la Unión Europea".

33 Pueden consultarse las estadísticas en CARMELI, Sara, La Constitution italienne..., op.cit., p. 230 y anejo estadístico.

34 El desarrollo de la Ley Comunitaria para 1993 será, esta vez sí, más acorde con las indicaciones de la Ley La Pergola, y tendrá al reglamento y al acto administrativo como principales instrumentos usados por el Gobierno.

35 Artículo 3 de la Ley La Pergola: el desarrollo podrá llevarse a cabo «también mediante atribución al Gobierno de delegación legislativa". 
gislativo viene en esta Ley acotado temporalmente, pues la Ley Comunitaria tiene vocación anual. Concretamente, el Gobierno deberá dictar, como plazo general, el decreto legislativo antes de 18 meses a contar desde la fecha de entrada en vigor de la ley comunitaria. En las delegaciones particulares contenidas en la ley comunitaria, suelen preverse plazos más perentorios de seis meses o, generalmente, de un año ${ }^{36}$. En definitiva, el Gobierno tiene un papel determinante tanto en la elaboración del Derecho europeo, como en la aplicación del mismo, y el Parlamento renuncia a ocupar una posición dominante. Veamos el contenido de esta delegación legislativa. Si la Ley Comunitaria habilita al Gobierno mediante delegación legislativa, ésta debería incluir taxativamente unos principios y criterios directivos. Ahora bien, dado que la Directiva ya incluye sus propios principios actores, la "especificación intermedia" de la Ley Comunitaria no es sencilla ${ }^{37}$. Además, se ha previsto en los primeros artículos de la ley comunitaria, unos "principios o criterios directivos generales de la delegación legislativa", a los cuales remite luego la ley en el artículo de autorización con$\operatorname{creta}^{38}$. Por otro lado, no es extraña la habilitación a dictar varios decretos legislativos mediante una única autorización ( uno o piú decreti legislativi). De esta manera, se rompe la tradicional relación entre la ley que delega y el decreto legislativo resultante.

La ley 128/1998 introduce una variación destacable cuando habilita para disponer decretos legislativos "integradores y correctores" para adaptar el ordenamiento nacional a la jurisprudencia del Tribunal de Justicia de las Comunidades Europeas. La práctica de los decretos legislativos correctores ya existía con anterioridad, y consiste en la posibilidad de dictar decretos legislativos sucesivos, sin mediar nueva autorización parlamentaria, con la condición de suponer correcciones al primer decreto legislativo, detectadas en la práctica aplicadora. Estos decretos legislativos ponen en cuestión el principio de instantaneidad de la delegación legislativa. Pues bien, la novedad radica aquí en la previsión de este nuevo tipo de decreto legislativo corrector, que viene justificado por la necesidad de dar cumplimiento, no ya a Directivas europeas, sino a principios jurisprudenciales. Así, por ejemplo, en el artículo 1,4 de la Ley Comunitaria para 2003, se habilita al Gobierno para dictar nuevos decretos legislativos, sin que medie nueva ley de delegación, esto es integradores y correctivos, hasta un año después de la entrada en vigor del decreto legislativo corregido $^{39}$. El espacio autorizado llega en ocasiones a los tres años y medio: dieciocho meses para dictar uno o varios decretos-legislativos, y un plazo añadido de dos años desde la entrada en vigor del decreto-legislativo ${ }^{40}$.

36 Por ejemplo, el art. 10 de la Ley Comunitaria para 2004 autoriza al Gobierno a adoptar un decreto legislativo en el plazo de seis meses desde la entrada en vigor de la misma.

37 CELOTTO, Alfonso, op.cit., p. 4.

38 Por ejemplo, el artículo 12.2 de la Ley Comunitaria para 2004.

39 Art. 1,4 de la Ley Comunitaria de 2003, de 31 de octubre de 2003, n.306. Sobre la técnica del decreto legislativo corrector, LUPO, Nicola, Deleghe e decreti legislativi "correttivi": esperienze, problemi, prospettive, Milán, 1996.

40 Así, el art. 25.3 de la Ley Comunitaria para 2004. 
El art. 10 de la Ley 128/1998 autoriza, de manera más amplia que en el pasado, una delegación legislativa que tiene visos de pluralidad, y que consiste en la adopción de textos únicos para ordenar el sistema normativo sobre las materias reguladas por la Directiva ${ }^{41}$. Este recurso al texto único busca clarificar el ordenamiento de desarrollo del Derecho europeo. En la misma línea, se establece la necesidad de una previsión expresa y con mención puntual de las disposiciones afectadas para aquellas derogaciones de preceptos contenidos en los textos únicos ${ }^{42}$. Se descarta por tanto el uso de la derogación tácita a tal efecto.

El decreto legislativo es el instrumento elegido como norma supletoria en caso de falta de desarrollo de las Directivas europeas por parte de las Regiones y Provincias autónomas, en materias que son competencia de estas últimas ${ }^{43}$. Los decretos legislativos adoptados en materias regionales adquieren vigor en la fecha de vencimiento del plazo de desarrollo del Derecho comunitario. Si, posteriormente, la Región hace uso de su competencia y dispone sobre la materia, el decreto legislativo decae a favor de la norma regional.

La Ley Comunitaria, finalmente, incorpora dos anejos, A y B, que contienen un listado de las Directivas que requieren un dictamen parlamentario previo (de manera general en el segundo supuesto (listado B), y en el primero (listado A) únicamente cuando se prevean sanciones penales). En ocasiones, se prevé también un elenco $\mathrm{C}$ de directivas susceptibles de desarrollo mediante reglamentos autorizados, siguiendo la técnica deslegalizadora del art. 17, 2 de la Ley 400/1978, que regula la actuación normativa gubernamental ${ }^{44}$. El dictamen del órgano parlamentario competente deberá darse dentro de los cuarenta días posteriores al envío del texto normativo por parte del Gobierno a las Cámaras. Pasado este plazo sin que hubiera dictamen, el decreto legislativo podrá ser dictado incluso sin el mismo.

En la Ley Comunitaria para 2005 es significativo que la única autorización de desarrollo del Derecho europeo mediante decreto legislativo sea en una materia delicada como es la lucha contra la financiación de las actividades terroristas ${ }^{45}$.

\section{VI.2. Reglamento autorizado (DESLEgalización)}

La posibilidad de recurrir a la técnica de la deslegalización es una de las notas destacadas de la ley comunitaria. El reglamento es, a priori, un instrumento normativo más adecuado para el desarrollo de disposiciones europeas que requieran una actuación rápida, con contenidos técnicos, o de poca rele-

41 También se encuentra esta previsión, por ejemplo, en el art. 5 de la Ley Comunitaria2003.

42 Art. 5.2 de la Ley Comunitaria para 2003.

43 Así, por ejemplo, el art. 1.5 de la Ley Comunitaria para 2003.

44 La Ley Comunitaria para 2005, de 25 de enero de 2006, por ejemplo, contiene un tercer listado, llamado "Allegato C".

45 Art. 22 de la Ley Comunitaria para 2005, de 25 de enero de 2006, núm. 29. 
vancia. El reglamento que da cumplimiento a la deslegalización prevista en la Ley Comunitaria lleva por nombre reglamento delegado, o mejor - pues evita confusiones con la delegación legislativa- reglamento autorizado ${ }^{46}$. Estos reglamentos pueden regular ámbitos actualmente cubiertos por una ley (reserva simplemente formal), derogando la previsión legal, aunque no pueden entrar en sectores reservados a la ley (reserva material). Ello ha sido alterado posteriormente, como veremos a continuación.

La Ley 128/1998 dispone de un apartado sobre la deslegalización, como las precedentes leyes comunitarias. Esta Ley modifica de manera considerable el modelo general de la Ley La Pergola. Quizás el cambio más significativo, en lo concerniente a la deslegalización, es el contenido en el art. 3, f). Se da por finalizada, en este precepto, la posibilidad abierta por la Ley Comunitaria de 1994, que consistía en la facultad de deslegalizar materias que no fueran reserva absoluta de ley mediante decreto legislativo. Ello significaba, de hecho, un instrumento en manos del Gobierno que alteraba notablemente la relación Ley-Reglamento fijada en la Constitución. Otra novedad, consiste en la habilitación gubernativa para desarrollar, mediante reglamento autorizado, no sólo las directivas contempladas en la ley comunitaria, sino también aquellas otras que habían sido objeto de transposición con anterioridad, y que son ahora modificadas o actualizadas por las Directivas en cuestión. Por otro lado, el reglamento podrá fijar incluso sanciones administrativas, si así lo prevé la directiva a aplicar.

Las críticas sobre el instrumento deslegalizador no se limitan a su previsión por parte de la ley comunitaria, sino a la actuación general del Ejecutivo. Sería deseable, para muchos autores, que la Ley Comunitaria previera una individualización de las disposiciones a derogar, así como una delimitación material del objeto deslegalizado. En su lugar, en muchas ocasiones, se autorizan de manera genérica las deslegalizaciones necesarias para el desarrollo de una determinada Directiva. Así, por ejemplo, el artículo 7 de la Ley Comunitaria para 2005 habilita sin más al Gobierno a adoptar decretos autorizados ("regolamenti autorizzati”) para desarrollar las Directivas contenidas en el Anejo C de la misma.

\section{VI.3. Reglamentos EJECUTIVOS Y ACTOS ADMINISTRATIVOS}

La Ley 128/1998 ha querido evitar que el desarrollo reglamentario venga realizado mediante simples actos administrativos (la llamada "fuga" del reglamento), y ha previsto expresamente dos apartados (reglamento y acto admi-

46 Sobre la deslegalización en Italia, DEMURO, Gianmario, Le delegificazioni: modelli e casi, Turín, 1995, TARLI BARBIERI, Giovanni, Le delegificazioni (1989-1995. Le dificile attuazione dell'art.17, secondo comma, della legge 23 agosto 1988, n.400. Más recientemente, MALFATTI, E., Rapporti tra deleghe legislative e delegificazioni, Turín, 1999. Un estudio comparado entre Francia, Italia y España en ROIG, Antoni, La deslegalización. Orígenes y limites constitucionales en Francia, Italia y España, Dykinson, Madrid, 2003, y bibliografía allí citada, destacando las contribuciones de Vezio CRISAFULLI, Antonio RUGGERI y Franco MODUGNO. 
nistrativo), donde la Ley Comunitaria de 1994 no distinguía. El desarrollo por reglamento deberá respetar las reglas del artículo 17 de la Ley 400/1988, que disciplina la potestad reglamentaria. Aunque el desarrollo reglamentario es una vía preferente en la Ley La Pergola, no siempre alcanza un porcentaje destacable en las preferencias del Ejecutivo, que antepone en ocasiones la delegación legislativa a éste. Sin embargo, el comportamiento interno a esta categoría es desigual. Así, la vía administrativa crece notablemente, a la vez que disminuye el peso de la vía de desarrollo por decreto del Consejo de Ministros ${ }^{47}$. De esta manera, la delegación legislativa y el desarrollo administrativo son las vías preferidas en las leyes comunitarias de 1994 en adelante. Así, la Ley 306, de 31 de octubre de 2003, Ley Comunitaria2003, confirma esta tendencia, aunque con una salvedad. En efecto, los artículos 6, 7, 8, 9, 10, 11, 13, 16, 18, 19, 20, 21, 23 у 24 de la Ley disponen directamente. No se trata ciertamente de cuerpos reguladores muy destacados, sino más bien de actualizaciones, revisiones y correcciones técnicas.

Esta tendencia se consolida con el nuevo modelo general de ley comunitaria, la Ley Buttiglione. En su artículo 11, se confirma el mecanismo deslegalizador, es decir que en materias actualmente disciplinadas por una ley, pero que no se encuentran dentro de la reserva absoluta de ley, pueden la Ley Comunitaria autorizar al reglamento gubernativo. Pero, además, en materias no disciplinadas actualmente por ninguna ley, y que no formen parte de ninguna reserva de ley, incluso meramente relativa, podrá la Ley Comunitaria autorizar el desarrollo del Derecho europeo mediante decretos ministeriales o interministeriales o actos administrativos generales por parte de un Ministro ${ }^{48}$. También habilita la ley en cuestión para dictar decretos ministeriales que corrijan aspectos técnicos en aplicación de aquellas directivas europeas meramente técnicas, que modifican otras directivas, y que no son autónomamente aplicables ${ }^{49}$.

\section{DICTAMEN OPCIONAL DE LAS COMISIONES PARLAMENTARIAS COMPETENTES}

Cuando la Ley Comunitaria ha previsto una delegación legislativa, o una deslegalización, el Parlamento puede contemplar, si lo desea, una garantía complementaria. Así, el proyecto de decreto legislativo o de reglamento autorizado será puesto a disposición de las comisiones parlamentarias competentes. Estos límites anómalos o "ulteriores" de los decretos legislativos, como han sido cualificados por ejemplo por Stefano Maria CICCONETTI, plantean dudas en cuanto a su naturaleza jurídica ${ }^{50}$. En todo caso, los controles parlamentarios

47 Los contenidos de las leyes comunitarias para 1994, para 1995-1997 y para 1998 son ejemplos destacados de esta tendencia.

48 Artículo 11.5 de la ley Buttiglione.

49 Artículo 13 de la Ley Buttiglione.

50 CELOTTO, Alfonso, op.cit., p. 4. 
en cuestión suponen una excepción a la previsión de la Ley 400/1988, reguladora de la potestad reglamentaria, que prevé únicamente los dictámenes parlamentarios para supuestos de delegación legislativa de duración temporal superior. Por ello, su inclusión en la Ley Buttiglione de 2005 busca la regularidad que no puede darle la previsión anual en una concreta ley comunitaria.

\section{LA POSICIÓN DE LA LEY COMUNITARIAEN EL SISTEMA DE FUENTES}

Tanto la Ley La Pergola como la Ley Buttiglione pretenden ser disposiciones sobre la producción normativa. Sin embargo, pese a que la disciplina de normas primarias, la distribución de competencias y el desarrollo del Derecho europeo son materia que la doctrina considera constitucionales, ninguna de estas dos leyes no ha tenido rango constitucional. Por ello, al igual que ha sucedido con la Ley 400/1988, que disciplina el poder reglamentario, la supuesta ley general comunitaria no ha sido hasta el momento más que una ley ordinaria, equivalente a las leyes comunitarias anuales posteriores ${ }^{51}$. Ello ha permitido que algunas leyes comunitarias incluyeran modificaciones más o menos significativas al modelo supuestamente general. Por ello, la Ley La Pergola parece "proponer" un sistema más que «imponerlo" ${ }^{52}$. Por esta razón, la Ley Buttiglione incorpora una cláusula de derogación expresa en su artículo 21. Cualquier reforma del modelo general debe preverse de manera expresa, y no ser ya consecuencia de una concreta regulación en una Ley Comunitaria anual. Veremos en las próximas leyes comunitarias si la medida evita la modificación puntual del modelo supuestamente general.

Formalmente, la Ley Comunitaria anual es muy parecida a la ley presupuestaria, dado que tiene también una vigencia temporal y su contenido es heterogéneo. Ahora bien, pese a ser fuente sobre la producción normativa, cuanto menos parcialmente pues contiene también una parte de regulación directa, la Ley Comunitaria no se sitúa formalmente a un nivel jerárquico superior al de las demás leyes ordinarias. Con todo, se discute en la doctrina si la capacidad que se reconoce a los reglamentos europeos de derogar normas formalmente constitucionales sería, a su vez, predicable de las leyes comunitarias ${ }^{53}$. Otro aspecto problemático lo constituye su función de parámetro de control de constitucionalidad de normas primarias, o en terminología italiana, su función de "norma interpuesta ${ }^{54}$. Concretamente, el respeto de los decretos legislativos autorizados a las directrices de la Ley Comunitaria plantea en el supuesto del desarrollo del Derecho europeo un reto añadido. En efecto, la Ley Comunitaria

51 Sobre la falta de resistencia de la Ley 400/1988 frente a derogaciones puntuales en leyes posteriores puede verse ROIG, Antoni, La deslegalización..., op.cit., esp. pp. 137-153.

52 CELOTTO, Alfonso, op.cit., p. 9.

53 CELOTTO, Alfonso, op.cit., p. 10.

54 Ver al respecto, SICLARI, Massimo, Le norme interposte, CEDAM, Padua, 1992. 
puede reenviar al Derecho Comunitario los contenidos de los principios que el Ejecutivo deberá respetar. De esta suerte, se habla en estos casos de "parámetro doblemente interpuesto". El Tribunal Constitucional valoraría indirectamente el respeto del Derecho europeo al comprobar que el decreto legislativo se estuviera ciñendo a lo fijado en la ley comunitaria ${ }^{55}$.

\section{CONCLUSIONES}

1. Las leyes comunitarias italianas han significado una mejora destacable en los plazos de transposición del Derecho europeo, que había sido su razón de ser. A pesar de ello, se ha cuestionado su eficacia, e incluso se las ha llegado a considerar responsables de mayores dilaciones, si cabe. Pese a todo, el Scoreboard, o porcentaje de directivas incumplidas había mejorado enormemente en 2001, para situarse en el 2,5\%. El 15 de noviembre del 2000, sobre 143 procedimientos por infracción en curso, sólo 38 concernían la no-transposición de Directivas. Otro dato que apunta al optimismo es la reducción de los plazos para la aprobación de las leyes comunitarias.

2. Por otro lado, algunas reformas del Reglamento de la Cámara de los Diputados parecen haber tenido más incidencia en el respeto de los plazos que las leyes comunitarias. Por consiguiente, la implicación del Parlamento en el proceso tiene parte de responsabilidad en el resultado.

3. Ahora bien, la Ley Comunitaria no ha conseguido "codificar" toda la aplicación del Derecho europeo, y existen supuestos de Directivas importantes que han tenido una vía de aplicación al margen del esquema de las leyes comunitarias. Ello ha llevado incluso a algún autor a afirmar la conveniencia de reservar la Ley Comunitaria como ley residual de aplicación del Derecho europeo, y no así como instrumento ordinario.

4. La tendencia apuntada en las leyes comunitarias más recientes confirma el peso creciente del Ejecutivo en la fase descendente o de ejecución del Derecho europeo. En efecto, puede detectarse un uso importante de las vías de desarrollo administrativo y de la delegación legislativa, y en mucha menor medida de la deslegalización, en detrimento del desarrollo legal. Sin embargo, las modificaciones introducidas a partir de la Ley Comunitaria1995-1997 en adelante, han reforzado el papel del Parlamento en la fase ascendente o de elaboración, gracias a una información detallada a las Cámaras en tiempo útil.

5. La participación de las regiones en la fase ascendente ha mejorado significativamente, aunque en la práctica deberá esperarse hasta confirmar que estos entes territoriales tienen un papel tan relevante como el que puede esperarse sobre el papel. En este sentido, la aparición reciente de las primeras leyes comunitarias regionales anunciaría una intervención regional más deter-

55 CARTABIA, Marta, "Principi della delega determinati con rinvio alle norme comunitarie e parametro doppiamente interposto", Giurisprudenza Costituzionale, 1993, 2044. 
minante también en la fase de aplicación. Con todo, el Gobierno dispone de importantes mecanismos de armonización que pueden desequilibrar en su favor la tarea de aplicación del Derecho europeo.

6. Las diferencias más significativas con el desarrollo de las Directivas en España pueden ser: El uso moderado del Decreto legislativo, a estos efectos, en España, pese a una primera etapa que hacía presagiar lo contrario (Ley 47/1985). La falta de decretos legislativos correctores en el caso español, es decir la ausencia de autorizaciones temporales no limitadas a un único desarrollo (y, por tanto, el respeto escrupuloso al principio de instantaneidad). El uso casi exclusivo del reglamento, por parte del Gobierno español, para desarrollar el Derecho europeo ${ }^{56}$.

ABstract. The implementation of the European Law by the States has not usually modified, in a strong way, their own sources of law. Nevertheless, the number, complexity and the technical regulation of many European laws, so as the need of respect due to the European Court decisions and sanctions, has forced sometimes to adapt some sources of law. One interesting example is the Italian communitarian law, an ordinary law, whose goal modifies some aspects of the Italian sources of law. In this sense, the legislative delegation to the Executive is no more limited to a single statute. The Executive can rule, during three years or more, without new delegations. In Spain, however, the sources of law system seems not to have suffered in a such way. We intend to prove that the implementation of the European Law changes in many ways the national sources of law system. The solutions adopted might be different than the Italian ones. In any case, we should perhaps look for such bidden changes, dues to implementation of European Law.

56 BUSTOS GISBERT, Rafael, "La transposición del Derecho comunitario por el Gobierno", documento presentado al II Congreso de la Asociación de Constitucionalistas de España, celebrado en la Universidad de Córdoba los días 25 y 26 de septiembre de 2003. 